\title{
Efektifitas Metode ABC (Activity Based Costing) dalam Analisis Perencanaan Obat JKN di Puskesmas Dagangan Kabupaten Madiun
}

\author{
Edy Bachrun \\ Program Studi Kesehatan Masyarakat, STIKES Bhakti Husada Mulia Madiun \\ Email: edybachrun@gmail.com
}

\begin{abstract}
Effectiveness of ABC Method in Planning Analysis of JKN Drugs in Dagangan Health Care Madiun City. Drug expenditure absorbs most of the health care budget. PHC was responsible for ensuring the used of available resources optimally aimed at achieving efficiency in cost control. Based on LPLPO at Dagangan health care 2015 showed an average supply of drugs JKN in primary health care Dagangan has excess stock that is as much as $93.18 \%$ (41) types of drugs than $100 \%$ (44) types of drugs. The purpose of this research was to determine the application of the ABC method in planning analysis of drugs in Dagangan health care Dagangan Madiun city. The design of this research was descriptive categorical, with a retrospective approach. Primary data obtained from an interview with Head of Health Centre and Head of Installation Pharmacy in Primary Health Care Dagangan while the secondary data obtained from LPLPO. The results showed that Dagangan health care use consumption method to planning the drug. By using the ABC analysis showed a group of JKN drugs that include group A as many as 8 types of drugs $(18,2 \%)$. Group B as many as 30 types of drugs $(68,2 \%)$. And group $C$ as much as 6 types of drugs $(13,6 \%)$. Based on these results, Dagangan health care needs to apply ABC analysis method to determine the priority drugs that need to be held, and there should be education and training for pharmacy personnel to increase knowledge about effective methods of drug design and efficient use of the budget.
\end{abstract}

Keywords: ABC analysis, Drug planning, Primary health care

\begin{abstract}
Abstrak: Efektifitas Metode ABC (Activity Based Costing) dalam Analisis Perencanaan Obat di Puskesmas Dagangan Kabupaten Madiun. Belanja obat menyerap sebagian besar anggaran pelayanan kesehatan. Puskesmas bertanggung jawab untuk memastikan penggunaan sumber daya yang tersedia secara optimal.Berdasarkan LPLPO di Puskesmas Dagangan tahun 2015 menunjukkan rata-rata persediaan obat JKN yang ada di Puskesmas Dagangan memiliki stok yang berlebih yaitu sebanyak $93,18 \%$ (41) jenis obat dari 100\% (44) jenis obat. Tujuan penelitian ini adalah mengetahui penerapan metode ABC (Activity Based Costing) dalam analisis perencanaan obat. Desain penelitian ini adalah deskriptif kategorik, dengan pendekatan retrospektif. Data primer diperoleh dari wawanacara dengan Kepala Puskesmas dan Kepala Instalasi Farmasi Puskesmas Dagangan, data sekunder diperoleh dari LPLPO. Hasil penelitian: Puskesmas Dagangan menggunakan metode konsumsi dalam merencanakan obat.Didapatkan hasil kelompok obat JKN yang masuk ke dalam kelompok A sebanyak 8 jenis obat $(18,2 \%)$. Kelompok B sebanyak 30 jenis obat $(68,2 \%)$. Dan kelompok C sebanyak 6 jenis obat $(13,6 \%)$. Saran: Pukesmas Dagangan perlu menerapkan metode analisis ABC untuk menentukan prioritas obat, perlu diadakan pendidikan dan pelatihan bagi petugas instalasi farmasi untuk menambah pengetahuan tentang metode perencanaan obat yang efektif dan efisien.
\end{abstract}

Kata kunci: Analisis ABC, Perencanaan obat, Puskesmas

Pengelolaan Obat merupakan salah satu kegiatan pelayanan kefarmasian, yang dimulai dari perencanaan, permintaan, penerimaan, penyimpanan, pendistribusian, pengendalian, pencatatan dan pelaporan serta pemantauan dan evaluasi. Tujuannya adalah untuk menjamin kelangsungan ketersediaan dan keterjangkauan Obat yang efisien, efektif dan rasional, meningkatkan kompetensi atau kemampuan tenaga kefarmasian, mewujudkan sistem informasi manajemen, dan melaksanakan pengendalian mutu pelayanan (Adiatmoko, 2012).

Kegiatan pengelolaan obat di puskesmas meliputi perencanaan kebutuhan obat, permintaan obat, penerimaan obat, penyimpanan obat, pendistribusian obat, pengendalian obat, pencatatan, pelaporan dan pengarsipan, serta pemantauan dan evaluasi pengelolaan obat. Perencanaan merupakan proses kegiatan seleksi obat untuk menentukan jenis dan jumlah obat dalam rangka pemenuhan kebutuhan Puskesmas. 
Tujuan perencanaan adalah untuk mendapatkan perkiraan jenis dan jumlah obat yang mendekati kebutuhan, meningkatkan penggunaan obat secara rasional, dan meningkatkan efisiensi penggunaan obat.

Salah satu sarana atau fasilitas yang diperlukan dalam pelayaan kesehatan kepada masyarakat secara optimal adalah perlunya daya dukung berupa ketersediaan obat untuk Pelayanan Kesehatan Dasar (PKD) agar sesuai dengan kebutuhan. Dalam rangka memenuhi kebutuhan obat publik perlu dilakukan upaya proses perencanaan yang akurat dan dapat dipercaya guna memenuhi kebutuhan obat publik di wilayah kerja Puskesmas. Guna menjamin ketersediaan kebutuhan obat untuk pelayanan dasar tersebut, Pemerintah telah mengatur melalui keputusan Menteri Kesehatan Republik Indonesia nomor 1121/Menkes/SK/XII/2008 tentang pedoman teknis pengadaan obat publik dan perbekalan kesehatan untuk pelayanan kesehatan dasar sebagai acuan dalam melaksanakan pengadaan obat publik dan perbekalan kesehatan di Kabupaten/kota (Adiatmoko, 2012).

Pengadaan barang/jasa secara elektronik atau e-procurement dapat dilakukan dengan e-tendering atau e-purchasing. e-Tendering merupakan tata cara pemilihan penyedia barang/jasa yang dilakukan secara terbuka dan dapat diikuti oleh semua penyedia barang/jasa yang terdaftar pada sistem elektronik. Sedangan e-purchasing obat merupakan tata cara pembelian obat sesudah sistem e-catalogue terbangun (Kementerian Kesehatan, 2014).

Berdasarkan Laporan Pemakaian dan Laporaan Permintaan Obat di Puskesmas Dagangan tahun 2013 menunjukkan bahwa rata-rata persediaan obat JKN yang ada di Puskesmas Dagangan memiliki stok yang berlebih yaitu sebanyak $93,18 \%$ (41) item obat dari $100 \%$ (44) item obat. Hal ini dapat mengakibatkan penumpukan obat dalam jenis obat tertentu, sehingga menyebakan penggunaan anggaran kurang efektif dan efisien, selain itu stok obat yang berlebih menyebabkan obat mengalami kadaluarsa.

Perencanaan kebutuhan obat di Puskesmas Dagangan dilakukan setiap 3 bulan sekali oleh Kepala Instalasi Farmasi puskesmas dengan menggunakan metode konsumsi. Dengan metode ini perencanaan kebutuhan obat ditambah dengan $10 \%$ dari pemakaian sebelumnya..

Oleh karena itu perlu dilakukan pengaturan dalam persediaan, terutama mengupayakan agar tidak terjadi overstock karena obat dengan nilai investasi besar menimbulkan biaya penyimpanan yang tinggi.
Dengan menyediakan obat-obatan dalam jumlah yang tepat dapat mengurangi biaya belanja obat-obatan untuk dapat menghemat anggaran biaya, sehingga anggaran belanja obat dapat digunakan untuk program puskesmas lain. Penggunaan metode konsumsi dan epidemiologi seperti yang sudah berjalan di Puskesmas Dagangan selama ini terdapat kelebihan stok obat.

Penelitian ini bertujuan untuk mengetahui penerapan metode ABC (Activity Based Costing) dalam analisis perencanaan obat di Puskesmas Dagangan Kabupaten Madiun. Hasil penelitian ini diharapkan dapat digunakan sebagai acuan perencanaan obat berdasarkan metode Activity Based Costing (ABC) bagi Puskesmas Dagangan Kabupaten Madiun.

\section{METODE}

Desain penelitian adalah rancangan penelitian yang terdiri atas beberapa komponen yang menyatu satu sama lain untuk memperoleh data dan/atau fakta dalam rangka menjawab pertanyaan atas masalah penelitian (Lapau, 2013). Sedangkan desain penelitian pada penelitian ini adalah deskriptif kategorik.

Instrumen atau alat yang digunakan dalam penelitian ini adalah berupa pedoman wawancara dibantu dengan perangkat alat perekam (voice recorder) untuk dokumentasi.

Data primer diproleh dari wawancara tentang perencanaan persediaan obat di Puskesmas Dagangan. Wawancara dilakukan secara langsung antara pewawancara dengan terwawancara. Pewawancara dalam penelitian ini adalah peneliti sendiri, sedangkan terwawancara adalah responden. Responden yang diwawancarai dalam penelitian ini adalah Kepala Perencana Obat, Pengelola Obat, Kepala Puskesmas Dagangan, dan dokter di Puskesmas Dagangan. Wawancara dilakukan dengan kuesioner untuk menentukan nilai kritis tiap item obat yang dipakai di Puskesmas Dagangan.

Data sekunder diperoleh dari telaah dokumen Puskesmas Dagangan seperti, daftar nama obat, jumlah pemakaian obat, dan harga obat.

Wawancara medalam dilakukan dengan 3 responden yaitu Kepala Perencana Obat, Pengelola Obat, Kepala Puskesmas Dagangan. Data yang dikumpulkan melalui wawancara mendalam dengan 3 responden tersebut dicatat dan dibuat transkrip wawancara. Data yang dianggap tidak penting dan tidak berhubungan dengan penelitian tidak dimasukkan dalam 
transkrip wawancara. Kemudian hasil wawancara yang penting dan berhubungan dengan penelitian ditranskrip ke dalam matriks berdasarkan pertanyaan penelitian.

Setelah melewati tahap wawancara dan pengumpulan data primer dan sekunder, selanjutnya analisis dilakukan untuk pengelompokkan obat berdasarkan metode $\mathrm{ABC}$. Untuk metode analisis $\mathrm{ABC}$ penelitian diawali dengan mengumpulkan dan menginput data mengenai daftar obat, jumlah pemkaian obat, dan harga obat dengan menggunakan Microsoft Excel. Kemudian membuat nilai pemakaian obat, menghitung investasi obat, menghitung nilai kritis untuk setiap jenis obat, menghitung Nilai Indeks Kritis (NIK) untuk setiap jenis obat, dan mengelompokkan setiap jenis obat ke dalam kelompok A, B, dan C. Setiap tahap dalam analisis mengikuti langkah-langkah sebagai berikut:

1. Menghitung nilai pakai

a. Menghitung total pemakaian obat

b. Data pemakaian obat dikelompokkan berdasarkan jumlah pemakaian. Diurutkan dari pemakaian terbesar sampai yang terkecil.

c. Kelompok A dengan pemakaian $70 \%$ dari keseluruhan pemakaian obat

d. Kelompok B dengan pemakaian 20\% dari keseluruhan pemakaian obat

e. Kelompok $\mathrm{C}$ dengan pemakaian $10 \%$ dari keseluruhan pemakaian obat.

2. Menghitug nilai investasi

a. Menghitung total investasi setiap jenis obat

b. Dikelompokkan berdasarkan nilai investasi obat. Diurutkan dari nilai investasi terbesar sampai terkecil

c. Kelompok A dengan nilai investasi $70 \%$ dari total investasi obat

d. Kelompok B dengan nilai investasi $20 \%$ dari total investasi obat

e. Kelompok C dengan nilai investasi $10 \%$ dari total investasi obat.

3. Menentukan nilai kritis obat

a. Menyusun kriteria nilai kritis obat

b. Membagikan kuesioner berupa daftar obat kepada dokter untuk mendapatkan nilai kritis obat, dengan kriteria yang telah ditentukan.

4. Menentukan nilai indeks kritis obat

Untuk menentukan NIK obat dengan menggunakan perhitungan sebagai berikut. NIK = Nilai Pakai + Nilai Investasi + $(2 \times$ Nilai Kritis)

5. Pengelompokkan obat ke dalam kelompok A, $\mathrm{B}$, dan $\mathrm{C}$ dengan kriteria :

a. Kelompok A dengan NIK 9.5 - 12 b. Kelompok B dengan NIK 6.5-9.4

c. Kelompok C dengan NIK 4-6.4

HASIL

Tabel 1. Pengelompokkan Obat JKN berdasarkan Analisis ABC Nilai Pakai

\begin{tabular}{ccccc}
\hline Kelompok & $\begin{array}{c}\text { Jumlah } \\
\text { Pemakaian }\end{array}$ & $\begin{array}{c}\text { \% } \\
\text { Pemakaian }\end{array}$ & $\begin{array}{c}\text { Jumlah } \\
\text { Item } \\
\text { Obat }\end{array}$ & $\begin{array}{c}\% \\
\text { Item } \\
\text { Obat }\end{array}$ \\
\hline A & $\begin{array}{c}20.600 \\
\text { butir }\end{array}$ & 15,9 & 7 & 15,9 \\
\hline B & 7.100 butir & 15,9 & 9 & 20,5 \\
\hline C & 3.725 butir & 68,2 & 28 & 63,6 \\
\hline Jumlah & $\begin{array}{c}31.425 \\
\text { butir }\end{array}$ & 100 & 44 & 100 \\
& & & & \\
\hline
\end{tabular}

Hasil perhitungan analisis $\mathrm{ABC}$ nilai pakai menunjukkan komposisi persentase jenis obat kelompok $\mathrm{A}, \mathrm{B}$, dan $\mathrm{C}$ berbanding lurus dengan persentase jumlah pemakainnya. Dari hasil perhitungan dapat dilihat masing-masing kelompok item obat kelompok A dengan penggunaan obat obat sebanyak 20.600 butir $(15,9 \%)$ persediaan, namun mencangkup $15,9 \%$ dari seluruh obat, kelompok B dengan penggunaan obat obat sebanyak 7.100 butir $(30,5 \%)$ persediaan, namun mencangkup $15,9 \%$ dari seluruh obat, serta kelompok $\mathrm{C}$ dengan penggunaan obat sebanyak 3.725 butir $(63,6 \%)$ persediaan, namun mencangkup $68,2 \%$ dari seluruh obat.

\section{A. Pengelompokkan Obat JKN Berdasarkan} ABC Investasi

Tabel 2. Pengelompokkan Obat JKN berdasarkan Analisis ABC Nilai Investasi

\begin{tabular}{|c|c|c|c|c|}
\hline Kelompok & $\begin{array}{c}\text { Nilai } \\
\text { Investasi }\end{array}$ & $\begin{array}{c}\% \\
\text { Investasi }\end{array}$ & $\begin{array}{c}\text { Jumlah } \\
\text { Item } \\
\text { Obat }\end{array}$ & $\begin{array}{c}\% \\
\text { Item } \\
\text { Obat }\end{array}$ \\
\hline $\mathbf{A}$ & $\begin{array}{c}\mathrm{Rp} \\
2.395 .950\end{array}$ & 70,9 & 12 & 27,3 \\
\hline B & $\begin{array}{c}\mathrm{Rp} \\
667.100\end{array}$ & 19,7 & 12 & 27,3 \\
\hline C & $\begin{array}{c}\mathrm{Rp} \\
316.575\end{array}$ & 9,4 & 20 & 45,4 \\
\hline Jumlah & $\begin{array}{c}\mathrm{Rp} \\
3.379 .625\end{array}$ & 100 & 44 & 100 \\
\hline
\end{tabular}

Hasil perhitungan analisis $\mathrm{ABC}$ nilai investasi menunjukkan kelompok obat JKN yang masuk ke dalam golongan kelompok A adalah sebanyak 12 item obat atau 27,3\% dari seluruh obat JKN dengan nilai investasi sebesar Rp 
2.395.950 atau 70,9\% dari seluruh total obat JKN di Puskesmas Dagangan. Kelompok obat JKN yang masuk ke dalam golongan kelompok B adalah sebanyak 12 item obat atau $27,3 \%$ dari seluruh obat JKN dengan nilai investasi sebesar Rp.667.100 atau $19,7 \%$ dari seluruh total obat JKN di Puskesmas Dagangan. Dan kelompok obat JKN yang masuk ke dalam golongan kelompok C adalah sebanyak 20 item obat atau $45,4 \%$ dari seluruh obat JKN dengan nilai investasi sebesar Rp.316.575 atau 9,4\% dari seluruh total obat JKN di Puskesmas Dagangan.

\section{B. Pengelompokkan Obat JKN Berdasarkan Nilai Kritis}

Tabel 3. Pengelompokkan Obat JKN berdasarkan Nilai Kritis

\begin{tabular}{crrr}
\hline $\begin{array}{c}\text { Total } \\
\text { Nilai }\end{array}$ & $\begin{array}{c}\text { Rata-rata } \\
\text { Nilai }\end{array}$ & Jumlah Obat & $\%$ \\
\hline 6 & 3 & 8 Item Obat & 18,2 \\
\hline 5 & 2,5 & 20 Item Obat & 45,5 \\
\hline 4 & 2 & 13 Item Obat & 29,5 \\
\hline 3 & 1,5 & 3 Item Obat & 6,8 \\
\hline
\end{tabular}

Berdasarkan hasil kuesioner yang diberikan kepada dokter untuk menentukan obat-obatan mana yang termasuk dalam golongan $\mathrm{X}, \mathrm{Y}$, dan $\mathrm{Z}$ diperoleh data obat yang mempunyai nilai rata-rata tertinggi yaitu sebesar 8 item obat $(18,18 \%)$ dengan nilai rata-rata sebesar 3 meliputi Amoksisilin Kapsul 500 mg, Bisoprolol, Glimepiride $2 \mathrm{mg}$, Haloperidol tab 1,5 $\mathrm{mg}$, Hidroklortiazid (HCT) tab $25 \mathrm{mg}$, Isosorbid Dinitrat Tab Sublingual $5 \mathrm{mg}$, Loperamid, dan Metformin $500 \mathrm{mg}$ Tab. Obat dengan nilai rata-rata 2,5 sebesar 20 item obat $(45,45 \%)$ meliputi Anthemoroid Doen Komb, Amlodipin 5 $\mathrm{mg}$, Acyclovir $400 \mathrm{mg}$, Difenhidramin $\mathrm{HCl}$ Inj 10 $\mathrm{mg} / \mathrm{ml}-1 \mathrm{ml}$, Fitomenadion (Vit.K) tab salut 10 mg, Kalsium Laktat (Kalk) Tab 500 mg, Kloramfenikol Salf Mata 1\%, Kloramfenikol Tetes Telinga 3\%, Klorfeniramin Maleat (CTM) Tab 4 mg, Kotrimoxazol Suspense, Kotrimoxazol Dewasa Tab, Lidokain comp inj, Metoklorpamid, Metronidazole Tab $500 \mathrm{mg}$, Omeprazole $20 \mathrm{mg}$, Parasetamol sirup $120 \mathrm{mg} / 5 \mathrm{ml}$, Parasetamol Tab $500 \mathrm{mg}$, Peridoxin $\mathrm{HCl} \mathrm{Tab} 10 \mathrm{mg}$, Propranolol HCL 10 MG, dan Salbutamol Tab $2 \mathrm{mg}$. Obat dengan nilai rata-rata 2 sebesar 13 item obat (29,54\%) meliputi Antasida Doen Salp Komb, Antibakteri Doen Salp Komb, Asam Folat, Betametason Krim 0,1\%, Deksametason tab 0,5 $\mathrm{mg}$, Domperidon $10 \mathrm{mg}$, Hidrokortison Krem 2,5\%, Klorpromazin $\mathrm{HCl} \mathrm{Tab}$ Salut $100 \mathrm{mg}$, Predinison Tab $5 \mathrm{mg}$, Ranitidine $150 \mathrm{mg}$, Salep 2-4 Kombinasi, Sianokobalamin (Vit.B12) Inj 500 $\mathrm{mcg} / \mathrm{ml}$, dan Tiamin $\mathrm{HCl}$ Mononitrat (Vit.B1) tab $50 \mathrm{mg}$. Serta obat dengan nilai rata-rata 1,5 sebesar 3 item obat $(6,82 \%)$ meliputi Ibuproven tab $200 \mathrm{mg}$, Ibuproven Tab $400 \mathrm{mg}$, dan Vit. B Komplek Tab.

\section{Pengelompokkan Obat JKN Berdasarkan Nilai Indeks Kritis}

Tabel 4. Pengelompokkan Obat JKN berdasarkan Nilai Indeks Kritis

\begin{tabular}{crr}
\hline Nilai Indeks Kritis & Jumlah Obat & \multicolumn{1}{c}{$\%$} \\
\hline 12 & 1 Item Obat & 2,3 \\
\hline 11 & 4 Item Obat & 9,0 \\
\hline 10 & 3 Item Obat & 6,8 \\
\hline 9 & 5 Item Obat & 11,4 \\
\hline 8 & 16 Item Obat & 36,4 \\
\hline 7 & 9 Item Obat & 20,4 \\
\hline 6 & 5 Item Obat & 11,4 \\
\hline 5 & 1 Item Obat & 2,3 \\
\hline Jumlah & 44 Item Obat & $\mathbf{1 0 0}$ \\
\hline
\end{tabular}

Berdasarkan tabel di atas menunjukkan kelompok obat JKN berdasarkan nilai indeks kritis obat. Kelompok obat JKN yang mempunyai nilai indeks kritis paling tinggi dengan NIK 12 yaitu berjumlah 1 item obat $(2,3 \%)$, obat dengan NIK 11 berjumlah 4 item obat $(9,1 \%)$, obat dengan NIK 10 berjumlah 3 item obat $(6,8 \%)$, obat dengan NIK 9 berjumlah 5 item obat $(11,36 \%)$, obat dengan NIK 8 sebesar 17 item obat (36,36\%), obat dengan NIK 7 berjumlah 9 item obat $(20,45 \%)$, obat dengan NIK 6 berjumlah 5 item obat $(11,36 \%)$, sedangkan obat JKN yang mempunyai nilai indeks kritis paling rendah dengan rata-rata NIK 5 yaitu 1 item obat $(2,3 \%)$.

\section{Pengelompokkan Obat JKN Berdasarkan ABC Nilai Indeks Kritis}

Tabel 5. Pengelompokkan Obat JKN berdasarkan Analisis ABC Nilai Indeks Kritis

\begin{tabular}{|c|c|c|c|}
\hline Kelompok & NIK & $\begin{array}{l}\text { Jumlah } \\
\text { Item }\end{array}$ & $(\%)$ \\
\hline A & $9,5-12$ & 8 & 18,2 \\
\hline B & $6,5-9,4$ & 30 & 68,2 \\
\hline C & $4-6,4$ & 6 & 13,6 \\
\hline Jum & & 44 & 100 \\
\hline
\end{tabular}

Hasil analisis perhitungan nilai indeks kritis obat yang termasuk dalam golongan kelompok A terdapat 8 item obat $(18,2 \%)$ meliputi Amoksisilin Kapsul 500 mg, Hidroklortiazid (HCT) tab 25 mg, Klorfeniramin Maleat (CTM) Tab $4 \mathrm{mg}$, Parasetamol Tab 500 mg, Peridoxin HCl Tab 10 g, Antasida Doen Salp Komb, Glimepiride 2 mg, dan 
Tiamin $\mathrm{HCl}$ Mononitrat (Vit.B1) tab $50 \mathrm{mg}$. Obat kelompok B terdapat 30 item obat $(68,2 \%)$ meliputi Amlodipin $5 \mathrm{mg}$, Kotrimoxazol Dewasa Tab, Metformin $500 \mathrm{mg}$ Tab, Metronidazole Tab $500 \mathrm{mg}$, Predinison Tab $5 \mathrm{mg}$, Anthemoroid Doen Komb, Acyclovir $400 \mathrm{mg}$, Bisoprolol, Deksametason tab 0,5 mg, Difenhidramin HCl Inj $10 \mathrm{mg} / \mathrm{ml}-1 \mathrm{ml}$, Fitomenadion (Vit.K) tab salut 10 $\mathrm{mg}$, Haloperidol tab $1,5 \mathrm{mg}$, Ibuproven tab 200 $\mathrm{mg}$, Isosorbid Dinitrat Tab Sublingual $5 \mathrm{mg}$, Kalsium Laktat (Kalk) Tab 500 mg, Kloramfenikol Tetes Telinga 3\%, Kotrimoxazol Suspense, Lidokain comp inj, Loperamid, Sianokobalamin (Vit.B12) Inj $500 \mathrm{mcg} / \mathrm{ml}$, Vit. B Komplek Tab, Domperidon $10 \mathrm{mg}$, Hidrokortison Krem 2,5\%, Kloramfenikol Salf Mata 1\%, Klorpromazin $\mathrm{HCl}$ Tab Salut $100 \mathrm{mg}$, Metoklorpamid, Omeprazole $20 \mathrm{mg}$, Parasetamol sirup $120 \mathrm{mg} / 5 \mathrm{ml}$, Propranolol HCL 10 MG, dan Salbutamol Tab $2 \mathrm{mg}$. Dan kelompok C terdapat 6 item obat (13,6\%) meliputi Antibakteri Doen Salp Komb, Asam Folat, Betametason Krim 0,1\%, Ranitidine 150 mg, Salep 2-4 Kombinasi, dan Salep 2-4 Kombinasi.

\section{PEMBAHASAN}

\section{Pengelompokkan Obat JKN Berdasarkan ABC Nilai Pakai}

Berdasarkan hasil perhitungan analisis nilai pakai menunjukkan persentase item obat dari masing-masing golongan $\mathrm{A}, \mathrm{B}$, dan $\mathrm{C}$ berbanding lurus dengan persentase jumlah pemakaiaannya. Hal ini berarti bahwa perencanaan obat di Puskesmas Dagangan kurang efektif dan efisien karena jumlah pemakaian dan persediaan obat di Puskesmas Dagangan tidak sesuai dengan komposisi persediaan pada umumnya. Menurut Febriawati (2013) dalam analisis ABC nilai pakai dikelompokkan menjadi tiga kelompok yaitu A, B, dan C. Kelompok A dengan pemakaian 70\% dari keseluruhan pemakaian obat. Kelompok B dengan pemakaian 20\% dari keseluruhan pemakaian obat. Dan kelompok C dengan pemakaian $10 \%$ dari keseluruhan pemakaian obat.

Berdasarkan analisis nilai pakai juga dapat dilihat bahwa ada banyak item obat dari masing-masing kelompok obat $\mathrm{A}, \mathrm{B}$, dan $\mathrm{C}$ yang moving-nya sangat rendah. Obat-obatan dengan moving yang rendah harus mendapatkan perhatian agar tidak terjadi penumpukan obat yang mempunyai resiko kadaluarsa yang dapat menyebabkan kurang efisiennya penggunaan dana untuk obat-obatan. Namun, juga perlu diperhatikan apakah obat-obatan tersebut masuk ke dalam kategori vital yang berarti harus tersedia dan tidak dapat diganti untuk proses perawatan, kekosongan obat tidak dapat ditoleransi, serta penggunaan obat dalam jumlah kecil.

\section{Pengelompokkan Obat JKN Berdasarkan ABC Investasi}

Berdasarkan hasil analisis nilai investasi di atas dapat dilihat bahwa persentase investasi berbanding terbalik dengan persentase item obat. Hal ini menandakan bahwa perencanaan obat JKN di Puskesmas Dagangan sudah efisien dalam penggunaan anggaran belanja untuk obat-obatan JKN, karena sudah sesuai dengan komposisi persediaan pada umumnya. Menurut Febriawati dalam analisis $\mathrm{ABC}$ nilai investasi dikelompokkan menjadi 3 kelompok yaitu A, B, dan C. Kelompok A dengan nilai investasi 70\% dari total investasi obat, kelompok B dengan nilai investasi $20 \%$ dari total investasi obat, dan kelompok $\mathrm{C}$ dengan nilai investasi $10 \%$ dari total investasi obat.

Berdasarkan analisis nilai investasi tersebut di Puskesmas Dagangan tetap perlu melakukan pengaturan dalam perencanaan dan persediaan, agar tidak terjadi penumpukkan stok atau overstock obat-obatan dengan nilai investasi tinggi, sehingga biaya untuk pengadaan obat dapat lebih efisien dan sesuai dengan obat-obatan yang dibutuhkan baik dalam jumlah maupun item obat. Hal ini sesuai dengan teori Anshari (2009) dalam fungsi penganggaran, semua rencana fungsi perencanaan dan penentuan kebutuhan dikaji lebih lanjut untuk kemudian disesuaikan dengan besarnya dana yang tersedia. Dengan kata lain fungsi penganggaran mempunyai hubungan timbal balik yang erat sekali dengan fungsi perencanaan, oleh karena itu perencanaan harus disusun secara realistis sesuai dengan pikiran, dana yang ada dan bila perencanaan sudah disepakati ada kepastian bahwa anggaran untuk mendukungnya terjamin. Dengan terbatasnya anggaran maka tidak jarang diperlukan feedback kepada pihak perencanaan dan user untuk dilakukan penyesuaian. Dalam batasan umum anggaran hakekatnya sebagai realisasi pendanaan suatu kegiatan operasional yang telah disesuaikan dengan feedback dan perencanaan user dengan mengingat efisiensi dan efektivitas.

\section{Pengelompokkan Obat JKN Berdasarkan Nilai Kritis}

Berdasarkan hasil perhitungan rata-rata nilai kritis dari hasil kuesioner penilaian dokter, 
obat dengan nilai kritis besar harus selalu tersedia di puskesmas karena obat-obat dengan nilai kritis tinggi merupakan obat yang tidak bisa digantikan oleh obat-obatan lain dan memiliki dampak paling besar terhadap kesehatan sehingga obat-obatan dengan nilai kritis tinggi tidak dapat ditoleransi kekosongannya. Menurut Febriawati (2013) kelompok X atau kelompok obat vital, adalah kelompok obat yang sangat essensial atau vital untuk memperpanjang hidup, untuk mengatasi penyakit penyebab kematian ataupun untuk pelayanan pokok kesehatan. Kelompok ini tidak boleh terjadi kekosongan. Kelompok Y atau kelompok obat essensial adalah obat yang bekerja kausal yaitu obat yang bekerja pada sumber penyebab penyakit logistik farmasi yang banyak digunakan dalam pengobatan penyakit terbanyak. Kekosongan obat dikelompok ini dapat ditolerir kurang dari 24 jam. Dan kelompok $\mathrm{Z}$ atau kelompok obat nonessensial, adalah obat penunjang agar tindakan atau pengobatan menjadi lebih baik, untuk kenyamanan atau untuk mengatasi keluhan. Kekosongan obat kelompok ini dapat ditolerir lebih dari 48 jam.

\section{Pengelompokkan Obat JKN Berdasarkan Nilai Indeks Kritis}

Berdasarkan hasil perhitungan menggunakan rumus nilai indeks kritis dapat dilihat obat-obat apa saja yang mempunyai nilai pakai, nilai investasi, dan juga nilai kritis yang tinggi. Perhitungan menggunakan rumus nilai indeks kritis sangat diperlukan dalam sebuah evaluasi perencanaan obat karena dengan menggunakan nilai indeks kritis kita dapat mengetahui obat-obatan yang masuk ke dalam kategori $\mathrm{ABC}$.

Dengan adanya perhitungan nilai indeks kritis ini pelayanan medis dapat mengetahui seberapa besar obat-obatan yang dibutuhkan dan yang dipakai di pelayanan medis khususnya disini di Puskesmas Dagangan. Hal ini sesuai dengan teori Febriawati (2013) bahwa analisis ABC Indeks Kritis digunakan untuk meningkatkan efisiensi penggunaan dana dengan pengelompokkan obat atau perbekalan farmasi, terutama obat-obatan yang digunakan berdasarkan dampaknya terhadap kesehatan.

\section{Pengelompokkan Obat JKN Berdasarkan ABC Nilai Indeks Kritis}

Berdasarkan hasil perhitungan dari analisis nilai pakai, nilai investasi, dan nilai indeks kritis dapat dilihat obat yang masuk ke dalam kelompok A yaitu sebesar 8 item obat (18,2\%), kelompok B
30 item obat $(68,2 \%)$, dan kelompok C 6 item obat $(13,6 \%)$. Pengelompokkan obat dengan menggunakan analisis $\mathrm{ABC}$ penting untuk digunakan karena untuk mengetahui dan meningkatkan efisiensi dalam penggunaan dana untuk belanja obat-obatan. Berdasarkan Febriawati (2013) Kelompok A dengan NIK tertinggi yaitu 12, mempunyai arti bahwa obat tersebut adalah obat dalam kategori kritis bagi sebagian besar pemakainya, atau bagi satu atau dua pemakai, tetapi juga mempunyai nilai investasi dan turn over yang tinggi. Dengan menggunakan metode analisis ini dapat diketahui obat-obatan apa saja yang mempunyai nilai pakai, nilai investasi, dan nilai kritis dari obat-obatan yang dipakai.

Dalam analisis $\mathrm{ABC}$ nilai kritis ini lebih menekankan pada nilai kritis obat daripada nilai pakai dan nilai investasi dari obat karena rumus untuk mengelompokkan ke dalam nilai indeks kritis ini menunjukkan bahwa nilai kritis dari obat memiliki nilai 2 kali lebih tinggi daripada nilai pakai dan nilai investasi. Hal ini sesuai dengan penelitian Febriawati (2013) bahwa analisis ABC Indeks Kritis digunakan untuk meningkatkan efisiensi penggunaan dana dengan pengelompokkan obat atau perbekalan farmasi, terutama obat-obatan yang digunakan berdasarkan dampaknya terhadap kesehatan.

Obat-obatan yang termasuk dalam golongan kelompok A perlu mendapatkan perhatian dalam sistem perencanaan dan pengadaan karena obat kelompok A memiliki nilai pakai dan nilai investasi tinggi, serta juga memiliki tingkat kekritisan yang tinggi karena efek dari obat tersebut dan penggunaannya yang tidak dapat digantikan dengan jenis obat-obatan lain sehingga obat-obatan yang masuk dalam kelompok ini tidak boleh terjadi kekosongan. obat-obatan yang tergolong dalam kelompok B ini merupakan obat dengan jumlah nilai pakai dan nilai investasi sedang, sehingga obat-obatan yang tergolong dalam kelompok ini juga memerlukan perhatian yang khusus setelah kelompok A. Obat yang masuk dalam golongan kelompok ini merupakan kelompok obat dengan nilai investasi dan nilai kritis yang kecil, sehingga obat yang tergolong dalam kelompok ini tidak memerlukan perhatian dan pengendalian yang ketat seperti pada kelompok A dan B.

\section{SIMPULAN}

Nilai pakai obat JKN di Puskesmas Dagangan yang masuk ke dalam golongan 
kelompok terbesar terdapat pada golongan $\mathrm{C}$ yaitu sebanyak 28 jenis obat atau $68,2 \%$, sedangkan kelompok A dan B mempunyai nilai yang sama yaitu masing masing golongan sebanyak 7 jenis obat atau $15,9 \%$.

Kelompok obat JKN di Puskesmas Dagangan berdasarkan analisis $\mathrm{ABC}$ nilai investasi. Kelompok obat JKN yang masuk ke dalam golongan kelompok terbesar terdapat pada golongan A yaitu sebanyak 12 jenis obat atau $27,3 \%$ dari seluruh obat JKN dengan nilai investasi sebesar Rp 2.395.950 atau 70,9\% dari seluruh total obat, sedangkan yang masuk ke dalam golongan terkecil terdapat pada golongan $\mathrm{C}$ yaitu sebanyak 20 jenis obat atau $45,4 \%$ dari seluruh obat JKN dengan nilai investasi sebesar Rp 316.575 atau 9,4\% dari seluruh total obat.

Kelompok obat JKN berdasarkan nilai kritis obat. Kelompok obat JKN yang masuk ke dalam nilai kritis paling tinggi dengan rata-rata nilai kritis 3 yaitu sebesar $18,2 \%$, sedangkan obat JKN yang masuk ke dalam nilai kritis paling rendah dengan rata-rata nilai kritis 1,5 yaitu sebesar 6,8\%.

Kelompok obat JKN berdasarkan nilai indeks kritis obat. Kelompok obat JKN yang mempunyai nilai indeks kritis paling tinggi

\section{DAFTAR PUSTAKA}

Adiatmoko, Sunar Nugroho. 2012. Analisis Perencanaan Kebutuhan Obat untuk UPT. Puskesmas di Wilayah Kerja Dinas Kesehatan Kota Pangkalpinang. Tesis. Pangkalpinang: Universitas Terbuka Pangkalpinang. Tersedia dalam http://www.pustaka.ut.ac.id/dev25/pdftesis 2/1340937.pdf

Anshari, Muhammad. 2009. Aplikasi Manajemen Pengelolaan Obat dan Makanan. Jogjakarta: Nuha Medika.

Febriawati, Henni. 2013. Manajemen Logistik Farmasi Rumah Sakit. Yogyakarta: Pustaka Baru. dengan NIK $12 \%$ yaitu sebesar 2,3\%, sedangkan obat JKN yang mempunyai nilai indeks kritis paling rendah dengan rata-rata NIK 5 yaitu sebesar 2,3\%.

Kelompok obat JKN di Puskesmas Dagangan berdasarkan analisis ABC indeks kritis. Kelompok obat JKN yang masuk ke dalam golongan kelompok A adalah sebanyak 8 jenis obat atau $18,2 \%$. Kelompok obat JKN yang masuk ke dalam golongan kelompok B adalah sebanyak 30 jenis obat atau $68,2 \%$. Dan kelompok obat JKN yang masuk ke dalam golongan kelompok $\mathrm{C}$ adalah sebanyak 6 jenis obat atau 13,6\%.

\section{SARAN}

Saran untuk Puskesmas Dagangan perlu diterapkan metode analisis ABC untuk menentukan prioritas obat yang perlu diadakan.

Selain itu, perlu diadakan pendidikan dan pelatihan bagi petugas instalasi farmasi Puskesmas Dagangan untuk menambah pengetahuan tentang metode perencanaan obat yang efektif dan efisien dalam penggunaan anggaran belanja.

Lapau, Buchari. 2013. Metode Penelitian Kesehatan Metode Penulisan Skripsi, Tesis, dan Disertasi. Yogyakarta: Yayasan Obor Indonesia.

Kementerian Kesehatan Republik Indonesia. Peraturan Menteri Kesehatan No. 30. 2014; Standar Pelayanan Kefarmasian Di Puskesmas.

Puskesmas Dagangan. 2013. Laporan Pemakaian dan Laporaan Permintaan Obat di Puskesmas Dagangan. Dinas Kesehatan Kabupaten Madiun Jawa Timur. 